\title{
DNA Ploidy and S-phase Fraction Analysis in Paediatric B-cell Acute Lymphoblastic Leukemia Cases: a Tertiary Care Centre Experience
}

\author{
Banothu Kiran Kumar' ${ }^{1}$ Prateek Bhatia ${ }^{2 *}$,Amita Trehan², Ajit Pal Singh ${ }^{2}$, Deepak \\ Kaul $^{2}$, Deepak Bansal ${ }^{2}$
}

\begin{abstract}
DNA ploidy is an important prognostic parameter in paediatric B-ALL, but the significance of the $S$-phase fraction is unclear. In present study, DNA ploidy was assessed in 40 pediatric B-ALL cases by flow cytometry. The DI (DNA index) and percentage of cells in S-phase were calculated using Modfit software. Aneuploidy was noted in 26/40 (65\%) cases. A DI of 1.10-1.6 (hyperdiploidy B) was noted in 20/40 (50\%) and 6/40 (15\%) had a DI>1.60 (triploid and tetraploid range). Some 14/40 (35\%) cases had a diploid DI between 0.90-1.05. None of the cases had a DI <0.90 (hypodiploid) or in the 1.06-1.09 (hyperdiploid A) range. The mean S-phase fraction was $2.6 \%$, with 24/40 (60\%) having low and 16/40 (40\%) high S-phase fractions. No correlation was noted with standard ALL risk and treatment response factors with DI values or S-phase data, except for a positive correlation of low S-phase with high NCI risk category $(\mathrm{p}=\mathbf{0 . 0 3 2})$. Overall frequency of hyperdiploidy in our cohort of B-ALL patients was very high $(65 \%)$. No correlation between hyperdiploidy B and low TLC or common B-phenotype was observed in our study as 42\% cases with DI 1.10-1.6 had TLC $>50 \times 10^{9}$ and $57.1 \%$ CD 10 negativity. The study also highlighted that $S$-phase fraction analysis does not add any prognostic information and is not a useful parameter for assessment in ALL cases. However, larger studies with long term outcome analysis are needed to derive definitive conclusions.
\end{abstract}

Keywords: ALL - DNA-index - ploidy - S-phase fraction - paediatric leukemia cases

Asian Pac J Cancer Prev, 16 (17), 7917-7922

\section{Introduction}

Acute lymphoblastic leukemia (ALL) is the most common malignancy in pediatric age group accounting for about $23 \%$ of all pediatric malignancies. The numerical and structural genetic aberrations are an important prognostic indicator in pediatric ALL and help to stratify patients into different risk groups. DNA ploidy assessment forms an important method to detect numerical genetic abnormalities and patients are categorized into favourable or unfavourable risk groups based on high hyperdiploid (>51 chromosomes) or hypodiploid (<46 chromosomes) DNA index respectively (Chaudhary et al., 2013; Wang., 2014). Though DNA ploidy assessment is a standard investigation in work up for ALL patients in the west, there are very few studies in the past from our subcontinent on the subject.All these studies have relied upon conventional cytogenetic method to highlight the incidence of various numerical or structural abnormalities. In a study by (Somnath et al., 2011), bone marrow samples of 31 cases of pediatric ALL were assessed for chromosomal abnormalities by conventional cytogenetics. They found an incidence of $51.2 \%$ (16/31) for hypodiploidy and 32.2\% (10/31) for hyperdiploidy. (Amare P et al., 1999), in their study on 78 pediatric ALL cases, found hypodiploidy in $38.4 \%$ and hyperdiploidy in $15 \%$ cases. In a study by (Jena et al., 2002), ploidy analysis was done in 44 cases (both pediatric and adult) and they found high hyperdiploidy in $6.8 \%$ cases and hypodiploidy in $63.6 \%$ cases. The above studies from our region show a high incidence of the high risk hypodiploidy group in both pediatric and adult ALL cases. However despite of these studies, the data on DNA ploidy frequencies in pediatric ALL population is limited. Moreover, correlation of DNA ploidy with early response to chemotherapy and other clinic-hematological parameters has not been extensively described. None of the above studies have employed the flow cytometric method to quantitatively analyze DNA ploidy based on DI values. Moreover, no study from our region has focused on the role of S-phase fraction in ALL cases. Hence, the present study was planned to look for frequencies of various DNA ploidy groups and significance of S-phase fraction, using flow cytometric method in our population. We have also tried to correlate the ploidy and S-phase data

${ }^{1}$ Department of Pediatrics, All India Institute of Medical Sciences, New Delhi, ${ }^{2}$ Pediatric Hemato-Oncology Unit, Department of Paediatrics, Post Graduate Institute of Medical Education and Research (PGIMER), Chandigarh, India *For correspondence: prateekbhatia@rediffmail.com 
with various clinical, hematological and early treatment response parameters.

\section{Materials and Methods}

The study was conducted from June 2013 to May 2014 and 40 consecutively diagnosed cases of acute lymphoblastic leukemia were enrolled during this period. Parents/guardian consent was taken before enrollment in the study. The cases were classified into different risk groups based on NCI risk criteria and treated as per modified UK MRC 2003 ALL protocol. Flow cytometric analysis of peripheral blood was done in cases with TLC $>5 \times 10^{9} / \mathrm{L}$ and $>20 \%$ blasts for DNA ploidy before start of chemotherapy. With each case a normal sample was run to calculate DNA index (DI). Both test sample and normal control were processed simultaneously within an hour. The peripheral blood mononuclear cells were prepared and purified using density-gradient centrifugation and the mononuclear cell layer was then aspirated into a separate tube. The cells were then counted under a haematocytometer to ensure presence of at least $1.0 \times 10^{6} / \mu \mathrm{l}$ cells in both test and control sample. The staining procedure was performed using cycle test plus DNA reagent kit (BD Biosciences Pvt. Ltd.). To mononuclear cells in the tube, $5 \mathrm{ml}$ of buffer solution was added and centrifuged at
Table 1. DNA Ploidy Classification based on DNA Index (DI) Values

\begin{tabular}{ll}
\hline DNA Index Value (DI) & Interpretation \\
\hline $0.90-1.05$ & Diploidy (46) \\
$<0.90$ & Hypodiploidy $(<46)$ \\
$1.06-1.09$ & Hyperdiploidy A (47-50) \\
$1.10-1.6$ & Hyperdiploidy B (51-68) \\
$1.6-2.1$ & Triploidy and tetraploidy (69 and above) \\
\hline
\end{tabular}

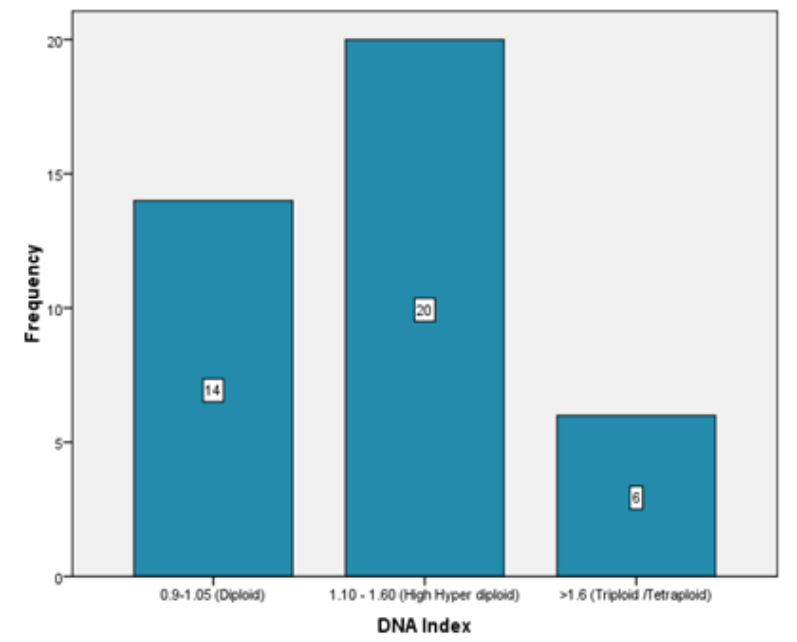

Figure 1. Histogram Showing DNA Index (DI) values in the Study Group

Table 2. Correlation of Demographic, Clinical, Hematological and Early Treatment Response Parameters with DNA Index (DI) Values

\begin{tabular}{|c|c|c|c|c|c|}
\hline $\begin{array}{l}\text { Parameter/ } \\
\text { DNA index }\end{array}$ & & $\begin{array}{l}0.90-1.09 \\
\text { (Diploid) }\end{array}$ & $\begin{array}{c}1.10-1.6 \\
\text { (High hyperdiploid) }\end{array}$ & $\begin{array}{c}>1.6 \\
\text { (Triploid \& tetraploid) }\end{array}$ & $\mathrm{p}$ value \\
\hline \multirow[t]{2}{*}{ Age } & $1-10$ years & 10 & 19 & 6 & \multirow[t]{2}{*}{0.075} \\
\hline & $<1 \&>10$ years & 4 & 1 & 0 & \\
\hline \multirow[t]{2}{*}{ Sex } & Male & 12 & 13 & 4 & \multirow[t]{2}{*}{0.388} \\
\hline & Female & 2 & 7 & 2 & \\
\hline \multirow[t]{2}{*}{$\mathrm{LN}$} & Lymphadenopathy & 9 & 16 & 4 & \multirow[t]{2}{*}{0.565} \\
\hline & No lymphadenopathy & 5 & 4 & 2 & \\
\hline \multirow{2}{*}{ Liver } & Hepatomegaly & 14 & 19 & 6 & \multirow[t]{2}{*}{0.599} \\
\hline & No hepatomegaly & 0 & 1 & 0 & \\
\hline \multirow[t]{2}{*}{ Spleen } & Splenomegaly & 12 & 16 & 3 & \multirow[t]{2}{*}{0.2} \\
\hline & No splenomegaly & 2 & 4 & 3 & \\
\hline \multirow[t]{2}{*}{$\mathrm{Hb}$} & Normal (>105 gm/L) & 1 & 2 & 2 & \multirow[t]{2}{*}{0.239} \\
\hline & Low $(<105 \mathrm{gm} / \mathrm{L})$ & 13 & 18 & 4 & \\
\hline \multirow[t]{2}{*}{ TLC } & $<50000$ & 6 & 12 & 3 & \multirow[t]{2}{*}{0.61} \\
\hline & $>50000$ & 8 & 8 & 3 & \\
\hline \multirow[t]{2}{*}{ Platelets } & Normal (>150000) & 1 & 2 & 0 & \multirow[t]{2}{*}{0.798} \\
\hline & Low $(<150000)$ & 13 & 19 & 6 & \\
\hline \multirow[t]{3}{*}{ Risk group } & Standard risk & 6 & 11 & 3 & \multirow[t]{3}{*}{0.078} \\
\hline & Intermediate risk & 4 & 9 & 3 & \\
\hline & High Risk & 4 & 0 & 0 & \\
\hline \multirow[t]{2}{*}{ Immunophenotype } & Common B ALL & 9 & 12 & 5 & \multirow[t]{2}{*}{0.574} \\
\hline & Pre B ALL & 5 & 8 & 1 & \\
\hline \multirow[t]{2}{*}{ CSF status } & Negative & 12 & 16 & 6 & \multirow[t]{2}{*}{0.507} \\
\hline & Positive & 2 & 1 & 0 & \\
\hline \multirow[t]{2}{*}{ Day 14 marrow } & RER & 11 & 13 & 6 & \multirow[t]{2}{*}{0.451} \\
\hline & SER & 3 & 2 & 0 & \\
\hline \multirow[t]{2}{*}{$\mathrm{S}$ phase fraction } & $<2.3 \%$ & 11 & 10 & 3 & \multirow[t]{2}{*}{0.213} \\
\hline & $>2.3 \%$ & 3 & 10 & 3 & \\
\hline \multirow[t]{2}{*}{ Day 30} & CHR & 7 & 10 & 4 & \multirow[t]{2}{*}{0.163} \\
\hline & NHR & 6 & 3 & 0 & \\
\hline \multirow[t]{2}{*}{ Outcome } & Alive & 11 & 15 & 4 & \multirow[t]{2}{*}{0.613} \\
\hline & Expired & 2 & 3 & 2 & \\
\hline
\end{tabular}


DNA Ploidy and S-phase Fraction Analysis in Paediatric B-Cell Acute Lymphoblastic Leukemia Cases

$2000 \mathrm{rpm}$ for $5 \mathrm{mts}$. Then supernatant was discarded and the above step was repeated twice. For reference tube, normal control cells were added into test cells in a ratio of 1:2; hence each sample had two tubes for analysis- one of sample cells and other mixture of sample and normal cells. After washings with buffer solution, $250 \mu$ l of trypsin buffer was added and tubes were kept at room temperature for 10 minutes. Then $250 \mu \mathrm{l}$ of RNAses were added and tubes kept for another 10 minutes at room temperature. Finally $200 \mu \mathrm{l}$ of propidium iodide as a DNA stain was added and mixed and the tubes were kept in refrigerator for 10 minutes. The samples were analyzed within 2 hours of staining on the same day of collection on a LSR II flowcytometer (Becton Dickinson). Before running samples on flowcytometer, the instrument linearity was checked using the DNA QC particle kit (BD Biosciences). This ensured optimal interpretation and validation of test results. For DNA Index (DI): ratio of mean G0/G1 peak of sample to mean of G0/G1 peak of normal control was analyzed. The Modfit software was used to calculate the DNA Index and \% cells in S-phase fraction in each case.

Many studies have taken different values for DNA index classification. We followed the classification by
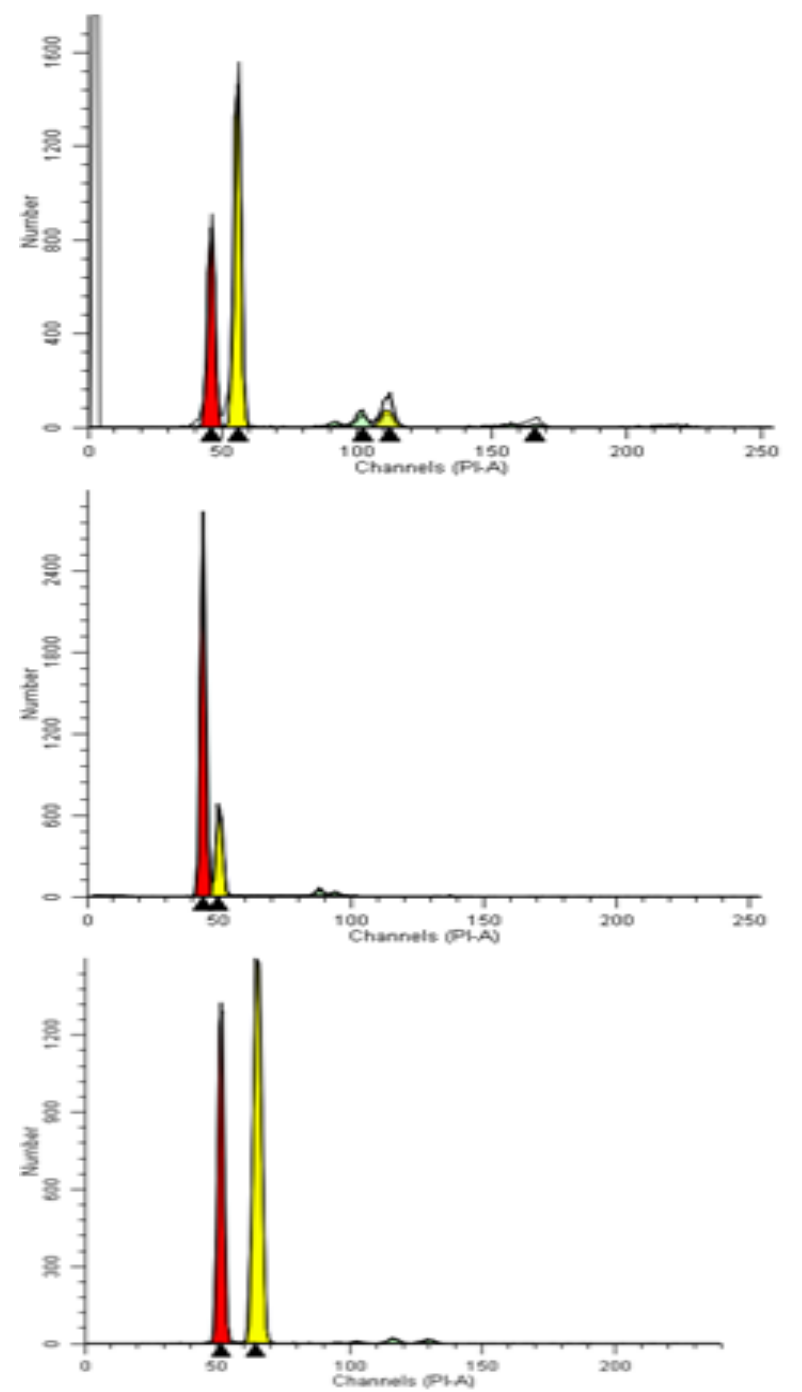

Figure 2. Hyperdiploidy B Type Ameuploidy Peaks with DI values $1.21,1.14$ and 1.27 Respectively in Various Case
(Basu et al., 2009) (Table 1). The early response to chemotherapy was assessed by bone marrow at day 14 and graded as RER (rapid early response/M1-<5\% blasts) or SER (slow early response/M2 \& M3- 5-20\% and $>21 \%$ blasts) and by day 30 peripheral blood criteria for complete hematological remission. The children were followed up till the completion of study. Of the 40 children, 3 left treatment within 14 days of start of treatment (leave against medical advice) and there were 2 induction related deaths within 14 days of treatment. Hence data for correlation of DNA index and S-Phase fraction with early response to treatment was available for 35 cases only.

Statistical analysis

Data was analyzed using SPSS software version 20. The data was categorized into different categories. The baseline variables in various groups were shown as mean \pm SD for quantitative variables and as percentages for qualitative variables. Univariate analysis was done to see the association between various groups using Chi square test or Fischer's exact test whichever was applicable. Logistic regression was applied to find the independent factors associated with outcome. Parametric test were done. The data was depicted graphically using bar diagrams and pie charts. A p value of $<0.05$ was considered significant.

\section{Results}

A prospective flow cytometric assessment of DNA ploidy status was done in 40 newly diagnosed cases of B-cell acute lymphoblastic leukemia in children aged $0-12$ years. The mean age of children enrolled in the study was 4.8 years. The majority of the children $(60 \%)$ in our study were in the peak age group of ALL occurrences i.e. $1-5$ years. In addition, $87.5 \%$ cases were within the favourable age group of 1-10 years. The B-ALL was more common in boys, $29 / 40(72.5 \%)$ as compared to girls $11 / 40(27.5 \%)$. At presentation, majority of the children had clinical evidence of lymphadenopathy (29/40-72.5\%), hepatomegaly (39/40-97.5\%) and splenomegaly (31/40$77.5 \%)$.

The mean hemoglobin concentration of children in the study was $72.33 \pm 24.1 \mathrm{gm} / \mathrm{L}$ and $87.5 \%$ of children enrolled in the study had anemia. The mean TLC count in the present study was $53.8 \times 10^{9} / \mathrm{L}$ with a median of $42.8 \times 10^{9} /$ L. $82.5 \%$ of children had elevated TLC and $47.5 \%$ had TLC greater than $50 \times 10^{9} / \mathrm{L}$ which is a known unfavourable cut off value for TLC in relation to treatment response and outcome. The mean platelet count in the present study was $40 \times 10^{9} / \mathrm{L}$ with a median of $21 \times 10 \% /$ L. Only $5 \%$ of children had normal platelet count and rest $95 \%$ had a low platelet count. None of the boys with B-ALL in our study had testicular involvement at presentation. Majority (34/37-91.9\%) of cases were CNS disease negative at diagnosis as defined by absence of leukemic cells from CSF. The common B-ALL phenotype (positive for CD 10) was the most common (26/40-65\%) subtype of B-ALL noted in our study as defined by EGIL criteria. None of our cases had the pro B-ALL phenotype, which is considered to be associated with hypodiploidy 
Table 3. Correlation of Demographic, Clinical, Hematological and Early Treatment Response Parameters with $S$-phase Fraction Values

\begin{tabular}{|c|c|c|c|}
\hline Parameter/ S phase fraction & $<2.6 \%$ & $>2.6 \%$ & $\mathrm{p}$ value \\
\hline \multicolumn{4}{|l|}{ Age } \\
\hline $1-10$ years & 19 & 16 & 0.051 \\
\hline$<1 \&>10$ years & 5 & 0 & \\
\hline \multicolumn{4}{|l|}{ Sex } \\
\hline Male & 18 & 11 & 0.665 \\
\hline Female & 6 & 5 & \\
\hline \multicolumn{4}{|l|}{$\mathrm{LN}$} \\
\hline Lymphadenopathy & 17 & 12 & 0.772 \\
\hline No lymphadenopathy & 7 & 4 & \\
\hline \multicolumn{4}{|l|}{ Liver } \\
\hline Hepatomegaly & 23 & 16 & 0.408 \\
\hline No hepatomegaly & 1 & 0 & \\
\hline \multicolumn{4}{|l|}{ Spleen } \\
\hline Splenomegaly & 18 & 13 & 0.643 \\
\hline No splenomegaly & 6 & 3 & \\
\hline \multicolumn{4}{|l|}{$\mathrm{Hb}$} \\
\hline Normal (>105 gm/L) & 3 & 2 & 1 \\
\hline Low $(<105 \mathrm{gm} / \mathrm{L})$ & 21 & 14 & \\
\hline \multicolumn{4}{|l|}{ TLC } \\
\hline$<50000$ & 15 & 6 & 0.121 \\
\hline$>50000$ & 9 & 10 & \\
\hline \multicolumn{4}{|l|}{ Platelets } \\
\hline Normal (>150000) & 1 & 1 & 0.767 \\
\hline Low $(<150000)$ & 23 & 15 & \\
\hline \multicolumn{4}{|l|}{ Risk group } \\
\hline Standard risk & 14 & 6 & 0.032 \\
\hline Intermediate risk & 6 & 10 & \\
\hline High risk & 4 & 0 & \\
\hline \multicolumn{4}{|l|}{ Immunophenotype } \\
\hline Common B ALL & 15 & 11 & 0.685 \\
\hline Pre B ALL & 9 & 5 & \\
\hline \multicolumn{4}{|l|}{ CSF status } \\
\hline Negative & 22 & 12 & 0.283 \\
\hline Positive & 1 & 2 & \\
\hline \multicolumn{4}{|l|}{ Day 14 marrow } \\
\hline RER & 19 & 11 & 0.324 \\
\hline SER & 2 & 3 & \\
\hline \multicolumn{4}{|l|}{ Day 30 status } \\
\hline CHR & 13 & 8 & 0.804 \\
\hline NHR & 6 & 3 & \\
\hline \multicolumn{4}{|l|}{ Outcome } \\
\hline Alive & 19 & 11 & 0.761 \\
\hline Expired & 4 & 3 & \\
\hline
\end{tabular}

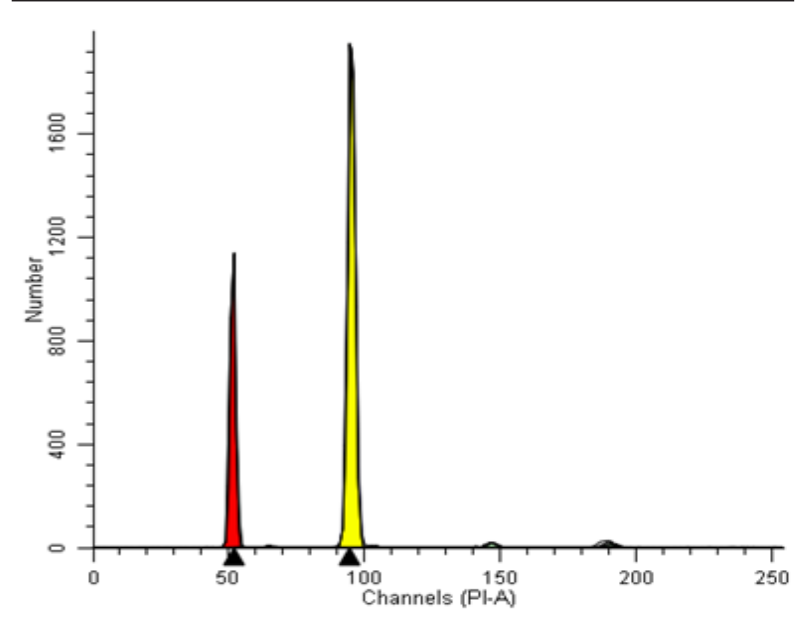

Figure 3. Triploid Aneuploid Peak with DI value 1.84 (>1.6 Group) in a Case and has a poor outcome.

Aneuploidy was noted in $26(65 \%)$ children and diploidy in $14(35 \%)$. Majority of the cases had a DNA index 1.10-1.6 (50\%), while 35\% cases had a DNA index of $0.90-1.05$ and $15 \%$ a DNA index $>1.6$ (Figure 1). There were no children with DNA index $<0.90$ (hypodiploidy), which is a known independent unfavourable prognostic marker. None of the cases had a DI between 1.06-1.09 (hyperdiploid A).

Majority of the children (95\%) with DI 1.10-1.6 were in the age group of 1-10 years but this was not statistically significant when compared with other ploidy groups. There was no significant correlation between DNA ploidy status and DNA index values with TLC at presentation, immunophenotype subtype, day 14 marrow response, CNS disease, day 30 hematological response and the final outcome (Table 2).

The mean $\mathrm{S}$ phase fraction in the study cohort was $2.6 \%$ and median was $2.3 \%$. Considering a cut off of $2.6 \%$ for low and high S-phase fraction, $60 \%$ of our cases had low $\mathrm{S}$ phase fraction and $40 \%$ had a high $\mathrm{S}$-phase fraction. A significant association of $\mathrm{S}$ phase fraction with risk category was noted in the present study (Table 3). All 4 children in high risk category had a low $\mathrm{S}$ phase fraction (p value-0.032).There was no significant correlation of $\mathrm{S}$ phase fraction with day 14 marrow response, day 30 hematological remissions and final outcome. Children with CNS disease negative at presentation had a good response to therapy as $90.6 \%$ had RER at day 14 marrow $(\mathrm{p}=0.07)$ and $75 \%$ were in CHR at day $30(\mathrm{p}=0.025)$.

\section{Discussion}

DNA ploidy which represents DNA content of cell is a well known prognostic marker and also forms a part of WHO 2008 classification as a separate clinical and prognostically distinct entity. The same is routinely assessed using conventional cytogenetics, which is a rather cumbersome technique and is dependent on presence of good quality metaphases. DNA ploidy is now being increasingly detected and expressed quantitatively by flow cytometric method in the form of DNA index. However, studies from our country employing the above technique are limited and data regarding prevalence of various ploidy abnormalities is also sparse.

Flow cytometric analysis for DNA ploidy was done on peripheral blood in all 40 children before starting chemotherapy. The technique quantitatively detects numerical abnormalities based on DNA index value. The DNA index range in the present study was 0.91-2.04 with a median of 1.14 . Out of 40 cases, $26(65 \%)$ had an aneuploid stem line and $14(35 \%)$ had a diploid stem line. The DNA index values in the aneuploid and diploid groups were as follows: 14 (35\%) had DNA index 0.90-1.05, 20 (50\%) had DNA index 1.10-1.6 and 6 (15\%) had DNA index $>1.6$ (Figure 2a-c \& 3).

We took a DI value of $\geq 1.10$ as cut-off for high hyperdiploidy in our study based on classification system used by (Basu et al., 2009), since in our study there were 10 cases who had a DNA index value between 1.10-1.16 and a distinct aneuploidy peak. In a study by 
(Raimondi et al., 1988) the DNA index values have been correlated to chromosome number on cytogenetics and it has been documented that a DI value between 1.10-1.16 corresponds to 51-54 number of chromosomes. (Khalifa et al., 1997) reported $40 \%$ aneuploidy of which $28.6 \%$ were hyperdiplopid and $11.4 \%$ were hypodiploid. In our study, the frequency of hyperdiploidy B (DNA index 1.10-1.6) was high as compared to other Western and Asian studies which show a range of 8.02-32.6\% (Fadrel et al., 1998; Yeoh eta 1., 2002; Mullighan., 2009; Shaikh et al., 2014; Lustosa et al., 2015). This could either be due the 1.10 cut off for DI used in our study as compared to 1.16 in other studies or an actual higher prevalence of a good prognostic marker in our region. However, the latter statement needs to be assessed in further larger prospective studies and also by correlation with conventional cytogenetic data.

None of the cases in our study had a DI value between 1.06-1.09 (hyperdiploid A or Less hyperdiploidy) and $<0.90$ (hypodiploid). Various studies from West quote a low incidence of hypodiploidy ranging from $0.3-7.6 \%$ (Olah et al., 2011; Woo et al., 2014), except for a study by (Khalifa et al., 1997), which shows an incidence of $11.4 \%$. Incidence of less hyperdiploidy (DI 1.06-1.09) also varies widely in different studies ranging from 5\%$16.3 \%$ (Raimondi et al., 1988; Raimondi et al., 2003). However, earlier studies from our subcontinent (Amare P et al., 1999; Jena et al., 2002; Somnath et al., 2011) show a high incidence of the high risk hypodiploidy group (38.4\%-63.6\%) in both pediatric and adult ALL cases. However, the above difference could be due to many reasons. Our study was focused on only pediatric (0-12 years) age group and B-cell immunophenotype positive cases, while studies by (Somnath et al., 2011) and (Amare P et al., 1999) have shown cumulative incidence of hypodiploidy in both B and T-cell ALL subgroups. In addition, the age range in study of (Amare et al., 1999) was $0-15$ years, while we recruited children till 12 years of age. (Jena et al., 2002) in their study show a very high frequency of hypodiploidy $(63.6 \%)$, but have not separately defined and analyzed adult and pediatric age groups or B and T-cell subtypes. It is well described in literature that majority of T-ALL cases are males and show hypodiploidy on ploidy analysis. Moreover, none of the above studies have defined ploidy subgroups based on DI values obtained by the flow cytometric method. Larger prospective studies from our region comparing both flow cytometric technique and conventional cytogenetics are still needed to precisely define the incidence of various DNA ploidy subgroups. There were a large number of cases with DI> $1.6(6 / 40-15 \%)$ in our study, of which 5 had tetraploid/near tetraploid DI values $(>1.98)$ and one case with triploid/near triploidy DI value (1.61-1.97). This is in contrast to a low (around 1\%) reported incidence in literature (Fadrel et al., 1998; Hilden et al., 2006) and in various studies which quote an incidence of 0.5\%-2.0\% (Hilden et al., 2006; Mullighan et al., 2009).

Univariate analysis was done with demographic, clinical, hematological parameters and response to therapy. There was no significant association of any of the parameter studied with DNA ploidy status and DI value. Among children with hyperdiploid B group (DI-
$1.10-1.6), 19 / 20$ (95\%) were in the age group of 1-10 years though this was not statistically significant. Day 14 marrow response was available in $35(87.5 \%)$ cases. The data was not available in 5 children ( 3 left treatments and 2 expired before day 14 of induction therapy). Among the 15 children with DNA index 1.10-1.6, in whom day 14 marrow data was available, $13(86 \%)$ had RER and 2 (14\%) SER. However, when compared with other ploidy groups, this difference was not statistically significant $(\mathrm{p}=0.451)$. The likely explanation for the absence of any correlation of DI value with age and day 14 marrow could be due to a small sample size or other factors like translocations/trisomies affecting prognosis. It has also been documented that children with 51-54 chromosomes (DI 1.10-1.16) fair relatively poorer than those with 55-68 chromosomes, who have a favourable outcome. Correlation of a low TLC at presentation and a common B-ALL phenotype is also well described in literature (Fadrel et al., 1998; Hilden et al., 2006) to be associated with the good prognostic high hyperdiploidy group (DI 1.16-1 .6). However in the present study no such correlation was noted as only 12/21 (57.1\%) cases with TLC $<50 \times 10^{9} / \mathrm{L}$ had DI values in hyperdiploid B range. Moreover, only 12/26 (46.1\%) cases with common B-ALL phenotype had DI 1.10-1.6. There were 8/14 (57.1\%) cases of pre- B ALL phenotype that also had a DI of 1.10-1.6 in our study.

The percentage S-phase fraction was also analyzed in all the cases enrolled in the study by flow cytometry. It defines the number of cells in the $S$ phase and the proliferative activity of the tumor cells and is a well recognized important prognostic factor in various malignancies. The role of S-phase fraction in leukemia as an independent prognostic marker is yet controversial. Studies have highlighted a cut off of $>6 \%$ for high S-phase fraction in bone marrow samples and $>4 \%$ for peripheral blood leukemic samples (Kaaijk et al., 2003). In the present study the S-phase fraction of cells ranged from $0.00 \%-17.59 \%$ with a mean of $2.6 \%$ and median of $2.3 \%$. In the diploid cell group the S-phase fraction varied from $0.36 \%-6.22 \%$, with a mean of $1.66 \%$ and median of $0.9 \%$ and in aneuploid cell group, S-phase fraction varied from $0.00 \%-17.59 \%$, with a mean of $3.11 \%$ and median of $2.29 \%$. In the present study, the mean value of $2.6 \%$ was taken as the cut off for classifying in to high and low S phase fraction. $24(60 \%)$ children had S-phase fraction $<2.6 \%$ and $16(40 \%)$ children had $S$ phase fraction $>2.6 \%$ indicating that leukemic cells in our cohort of B-ALL patients have relatively low proliferative activity. Univariate analysis was done to find out association of $\mathrm{S}$ phase fraction with other parameters. A significant association was noted with risk category. All 4 (100\%) children in high risk category had $\mathrm{S}$ phase fraction $<2.6 \%$. This in contrast to the usual outcome, where children in high risk category have more disease burden and higher proliferative activity. This could be due to small sample size and other factors affecting tumor and further studies are required to substantiate the same. There was no significant association with age, sex, DNA index, CNS disease, day 14 marrows, day 30 remission and outcome. This in contrast to study by (Fouad et al., 2002) that 
Banothu Kiran Kumar et al

showed good response to therapy and outcome in children with low proliferative activity. In their study, children with low $\mathrm{S}$ phase fraction achieved complete remission in $88.9 \%$ compared to children with high $\mathrm{S}$ phase fraction where complete remission was achieved in only in $27.3 \%$.

The present study though provides new insights into relative frequencies of various DNA ploidy groups based on DI values and adds to the limited data available on the subject from our region, it nevertheless suffers from limitations like a small sample size, absence of long term follow up data and no correlation of DI values with conventional cytogenetics.

Take home message: Hyperdiploidy B (DI value 1.101.6) was the most common aneuploidy in our cohort of pediatric B-cell ALL children. However, there was no significant association of DI values with early response to chemotherapy or to underlying biological standard risk factors.

S-phase fraction analysis in pediatric leukemias is not likely to yield any significant prognostic information and is not recommended as a useful parameter for prognostication.

\section{References}

Amare P, Gladstone B, Varghesse C, Pai S, Advani S (1999). Clinical significance of cytogenetic findings at diagnosis and in remission in childhood and adult Acute Lymphoblastic leukemia: Experience from India. Cancer Genet Cytogenet, 110, 44-53.

Basu O, Zolzer F, Uma DP (2009). DNA Ploidy - A Prognostic Factor of Acute Lymphoblastic Leukemia (ALL) in Childhood. Asian J Exp Sci, 23, 33-8.

Faderl S, Kantarjian HM, Talpaz M, Estrov Z (1998). Clinical significance of cytogenetic abnormalities in adult acute lymphoblastic leukemia. Blood, 91, 3995-4019.

Foud M AT, Maha R AW, Hala A AA, Amal A Z, Saed S E (2002). Flow cytometric assessment of nuclear DNA ploidy and proliferative activity in acute lymphoblastic leukemia. $J$ Nat Egyptian Cancer Inst, 14, 303-10.

Hilden JM, Dinndorf PA, Meerbaum SO, et al (2006). Children's Oncology Group. Analysis of prognostic factors of acute lymphoblastic leukemia in infants: report on CCG 1953 from the Children's Oncology Group. Blood, 108, 441-51.

Jena RK, Patnaik SC, Sahu GR, Ray B, Swain K (2002). Secondary chromosomal abnormalities in Acute lymphoblastic Leukemia. Caryologia, 55, 349-55.

Kaaijk P, Kaspers GJL, Van-Wering ER, Broekema GJ, Loonen AH, Hählen K (2003). Cell proliferation is related to in vitro drug resistance in childhood acute leukaemia. Br J Cancer. $\mathbf{8 8}, 775-81$.

Khalifa AS, El-Kardani TA, Faeyk MH (1997). Flowcytometric study childhood acute leukemia immunophenotype and DNA analysis. Egypt J Haematol, 22, 1-23.

Lustosa de Sousa DW, de Almeida Ferreira FV, Cavalcante Félix FH, de Oliveira Lopes MV (2015). Acute lymphoblastic leukemia in children and adolescents: prognostic factors and analysis of survival. Rev Bras Hematol Hemoter. 37, 223-9.

Mullighan CG, Su X, Zhang J, et al (2009). Children's Oncology Group. Deletion of IKZF1 and prognosis in acute lymphoblastic leukemia. N Engl J Med, 360, 470-80.

N Chaudhary, A Borker (2013). Significance of karyotyping in childhood acute lymphoblastic leukemia. Pediatric Oncall Journal, 10, 39-41.

Olah E, Balogh E, Pajor L, Jakab Z (2011). Ten-year experiences on initial genetic examination in Childhood Acute Lymphoblastic Leukemia in Hungary (1993-2002): Technical Approaches and Clinical Implementation. Pathol Oncol Res, 17, 81-90.

Raimondi SC, Behm FG, Roberson PK, et al (1988). Cytogenetics of childhood T-cell leukemia. Blood, 72, 1560-6.

Raimondi SC, Zhou Y, Mathew S, et al (2003). Reassessment of the prognostic significance of hypodiploidy in pediatric patients with acute lymphoblastic leukemia. Cancer, $\mathbf{9 8 ,}$ 2715-22.

Shaikh MS, Ali SS, Khurshid M, Fadoo Z (2014). Chromosomal abnormalities in Pakistani children with acute lymphoblastic leukemia. Asia Pac J Cancer Prev, 15, 3907-9.

Somnath P, Rajlaxmi S, Pranati M, Rupa Das, Sukumar C, Raghumani M (2011). Cytogenetic profile of pediatric acute lymphoblastic leukemia (ALL): Analysis of 31 cases with review of literature. Caryologia, 64, 33-41.

Woo JS, Alberti MO, Tirado CA (2014). Childhood B-acute lymphoblastic leukemia: a genetic update. Experimental Hematology \& Oncology, 3, 1-14.

XM Wang (2014). Advances and issues in flow cytometric detection of immunophenotypic changes and genomic rearrangements in acute pediatric leukemia. Transl Pediatr, 3, 149-55.

Yeoh EJ, Ross ME, Shurtleff SA, et al (2002). Classification, subtype discovery and prediction of outcome in pediatric acute lymphoblastic leukemia by gene expression profiling. Cancer Cell, 1, 133-43. 